\title{
Conservação e germinação in vitro de pólen de milho (Zea mays subsp. mays)
}

\author{
CÍCERO ALMEIDA ${ }^{1,4}$, ADRIANE LEITE DO AMARAL $^{2}$, \\ JOSÉ FERNANDES BARBOSA NETO ${ }^{3}$ MARIA JANE CRUZ DE MELO SERENO ${ }^{3}$
}

(recebido: 30 de dezembro de 2010; aceito: 08 de julho de 2011)

\begin{abstract}
Conservation and in vitro germination of pollen of maize (Zea mays subsp. mays)). The storage of pollen can be considered an important tool for maize breeding programs, allowing to preserve, under artificial conditions, the viability of male gametes and extend the possibilities of crossings regardless of flowering time of parental varieties. This study aimed to evaluate the culture media for in vitro germination of corn pollen and analyze storage conditions. To examine viability, six different culture media containing sucrose, boric acid, calcium chloride and agar were evaluated. For pollen preservation, two temperatures $\left(4^{\circ} \mathrm{C}\right.$ and $\left.-20^{\circ} \mathrm{C}\right)$ and two agents of pollen dehydration (silica gel and hydrated calcium chloride) were evaluated. The high values of pollen viability up to 30 days of storage indicate that dehydration in silica gel and storage at $4{ }^{\circ} \mathrm{C}$ preserve the viability of corn pollen. The culture medium that provided the highest germination rate in vitro was the composition of $0.7 \%$ agar, $17 \%$ sucrose, $0.01 \%$ boric acid and $0.03 \%$ calcium chloride hydrate.
\end{abstract}

Key words - breeding, plant breeding, storage of pollen

RESUMO - (Conservação e germinação in vitro de pólen de milho (Zea mays subsp. mays)). O armazenamento de pólen é uma importante ferramenta para programas de melhoramento de milho, permitindo preservar, sob condições artificiais, a viabilidade de gametas masculinos e ampliar as possibilidades de cruzamentos, independente da época do florescimento das variedades genitoras. O presente trabalho teve como objetivo avaliar meios de cultivo para a germinação in vitro de pólen de milho e analisar condições de conservação. Para avaliar viabilidade, foram testados seis meios de cultivo, contendo sacarose, ácido bórico, cloreto de cálcio hidratado e ágar. Para a conservação de pólen foram analisadas duas temperaturas $\left(4^{\circ} \mathrm{C}\right.$ e $-20^{\circ} \mathrm{C}$ ) e dois agentes desidratantes de pólen (sílica gel e cloreto de cálcio hidratado). Os altos valores de viabilidade do pólen no período de até 30 dias de armazenamento indicam que a desidratação em sílica gel e armazenamento a $4{ }^{\circ} \mathrm{C}$ conservam a viabilidade de pólen de milho. O meio de cultivo que proporcionou a maior taxa de germinação in vitro foi com a composição de $0,7 \%$ de ágar, $17 \%$ de sacarose, $0,01 \%$ de ácido bórico e $0,03 \%$ de cloreto de cálcio hidratado.

Palavras-chave - cruzamentos, estocagem de pólen, melhoramento genético

\section{Introdução}

O estabelecimento de metodologia de conservação de pólen é de grande interesse nos programas de melhoramento porque permite realizar cruzamentos entre genótipos sem sincronia reprodutiva, como materiais não adaptados e espécies afins (Connor \& Towill 1993). A preservação da viabilidade de pólen envolve redução do teor de umidade e armazenamento em baixas temperaturas (Akihama et al. 1978). Em geral, a umidade do pólen próxima de $10 \%$ tem permitido manter a viabilidade (Sprague \& Johnson 1977), pelo

1. Universidade Federal de Alagoas, Campus Arapiraca, Avenida Manoel Severino Barbosa s/n, Rodovia AL 115, km 6,5, 57309005 Bom Sucesso, Arapiraca, AL, Brasil.

2. Embrapa Tabuleiros Costeiros - Unidade de Execução de Pesquisa e Desenvolvimento de Rio Largo - UEP, Centro de Ciências Agrárias, BR104, km 05, Rio Largo, AL, Brasil.

3. Universidade Federal do Rio Grande do Sul, Faculdade de Agronomia, UFRGS, 91501-970 Porto Alegre, RS, Brasil.

4. Autor para correspondência: cicerocarlos@hotmail.com fato de evitar a formação de cristais de gelo no processo de congelamento. Caso haja formação desses cristais, ocorre o rompimento da membrana celular, destruindo o pólen. O pólen das espécies vegetais pode ser classificado como tolerantes ou sensíveis à desidratação, em que o pólen binucleado é mais tolerante e o pólen trinucleado é sensível (Hughes \& Lee 1991). O milho possui pólen trinucleado, o que o torna um material mais difícil para armazenar. Fehr \& Hadley (1980) afirmam que pólen de milho possui uma membrana muito fina, resultando em baixa proteção e que a viabilidade pode ser perdida, devido à desidratação, em um período de curto tempo. Além disso, Souza (1988) mostrou que em milho a segunda divisão meiótica diminui as reservas do pólen, diminuindo a capacidade de manter a viabilidade ao longo do tempo.

A viabilidade do grão de pólen, que é uma medida de fertilidade masculina, pode ser determinada por método direto, com uso de técnicas de indução à germinação in vitro (Pio et al. 2007) ou in vivo (Ferreira et al. 2007) e, por método indireto baseado em parâmetros citológicos, 
como a coloração (Colas \& Mercier 2000). No emprego da coloração, é frequente o uso de corantes nucleares como carmim acético e azul de anilina, os quais colorem apenas pólens funcionais. Apesar de ser um procedimento simples e de baixo custo, não reflete a capacidade de germinação no caso de grãos de pólen viáveis com exina espessa e/ou mucilaginosa, que não se colorem e ocasionam subestimativas (Alexander 1969, 1980), assim como, no caso de grãos de pólen que se colorem, mesmo sendo incapazes de germinar, por problemas no desenvolvimento do tubo polínico, ocasionando superestimativas da viabilidade do pólen (Galleta 1983).

A germinação in vitro é uma técnica que simula condições do estigma, induzindo a germinação do tubo polínico e que apresenta alta correlação com a fertilização a campo. No entanto, a germinação in vitro tende a superestimar a fertilização in vivo porque desconsidera a influência de fatores importantes como a receptividade do estigma, barreiras genéticas e influência do ambiente (Barnabás et al. 1988). A técnica de germinação in vitro consiste em germinar uma pequena amostra em um meio de cultura apropriado, com visualização em microscópio óptico. Entre os fatores que afetam a germinação estão os componentes químicos e consistência do meio de cultura, tempo e condições de incubação. $O$ pólen das angiospermas necessita, para promoção da germinação, fontes de carbono (sacarose), de boro (ácido bórico) e, frequentemente de mais outros nutrientes, como cálcio (cloreto de cálcio) (Galleta 1983). No meio de cultura, o açúcar fornece energia para o processo de desenvolvimento do tubo polínico e proporciona equilíbrio osmótico entre o pólen e a solução de germinação (Stanley \& Linskens 1974, Miranda \& Clement 1990). A adição de boro apresenta resposta variável conforme a espécie vegetal, contudo, seu mecanismo de ação consiste em formar complexo ionizável açúcar-borato, o qual afeta a membrana celular e é capaz de incrementar a percentagem de germinação e o comprimento do tubo polínico (Thompson \& Batjer 1950, Pfahler 1967). O cálcio adicionado ao meio-de-cultura propicia menor permeabilidade e confere uma aparência mais rígida ao tubo polínico (Stanley \& Linskens 1974).

O presente trabalho teve como objetivo avaliar meios de cultivo para a germinação in vitro de pólen de milho e determinar condições adequadas de estocagem, que proporcionem maior conservação da viabilidade.

\section{Materiais e métodos}

Para assegurar uma análise mais precisa, previamente foram testados seis diferentes meios de germinação de tubo polínico, conforme descrito na tabela 1. Para preparo de meio de cultura, os componentes foram adicionados a um recipiente e aquecidos até se dissolverem (evitando fervura). Após atingir temperatura de $27{ }^{\circ} \mathrm{C}$ foram adicionados os pólens coletados do híbrido simples (AS-3466, cultivado na Estação Experimental da Faculdade de Agronomia, Porto Alegre, RS) e mantidos nessa temperatura por 2 horas para germinação e corados com carmim propiônico $1 \%$ para análise. As análises foram feitas em 200 grãos de pólens, computando os que germinaram. A eficiência dos meios foi analisada no delineamento inteiramente casualizado com duas repetições e as médias comparadas pela estatística DMS (diferença mínima significativa) obtida pelo teste $t$ de student $(\alpha=5 \%)$. O meio que apresentou maior eficiência na germinação do tubo polínico foi utilizado para avaliar as condições de estocagem, utilizando as mesmas condições.

Tabela 1. Composição de meios de cultura para germinação in vitro de pólen de milho.

Table 1. Composition of culture media for in vitro germination of maize pollen.

\begin{tabular}{ccccc}
\hline $\begin{array}{c}\text { Meio de } \\
\text { cultura }\end{array}$ & $\begin{array}{c}\text { Ágar } \\
(\%)\end{array}$ & $\begin{array}{c}\text { Sacarose } \\
(\%)\end{array}$ & $\begin{array}{c}\text { Ácido } \\
\text { bórico } \\
(\%)\end{array}$ & $\begin{array}{c}\text { Cloreto de } \\
\text { cálcio } \\
(\%)\end{array}$ \\
\hline M1 & - & 25 & - & - \\
M2 & - & 10 & 0,04 & - \\
M3 & - & 20 & - & 0,15 \\
M4 & 1,0 & 15 & 0,03 & - \\
M5 & - & 10 & 0,03 & 0,15 \\
M6 & 0,7 & 17 & 0,01 & 0,03 \\
\hline
\end{tabular}

Foi utilizada uma mistura de pólen dos genótipos de milho doce BR402 e DO1880, cultivado na Estação Experimental Agronômica (EEA/UFRGS), Eldorado do Sul, RS. A coleta do pólen foi feita durante a antese no período da manhã, utilizando diversas plantas. Após a coleta, o material foi conduzido ao laboratório e colocado em quatro recipientes e mantidos por 48 horas em dois sistemas de desidratação: cloreto de cálcio hidratado $\left(\mathrm{CaCl}_{2} 2 \mathrm{H}_{2} \mathrm{O}\right)$ e sílica gel (Sigma 7325). Após esse período, cada recipiente foi lacrado e mantido em temperatura de $4{ }^{\circ} \mathrm{C}$ ou $-20{ }^{\circ} \mathrm{C}$, durante 30 dias. A avaliação das condições de estocagem foi feita por meio da germinação do tubo polínico em meio de cultivo conforme descrito acima, realizada após a desidratação (antes de resfriamento), aos 10, 20 e 30 dias de estocagem. Foram avaliados 100 grãos de pólen e os dados foram analisados em modelo de regressão linear. Para normalizar as diferenças de viabilidade inicial (antes de resfriar), os resultados foram representados graficamente pela viabilidade relativa, ou seja, o quanto diminuiu a viabilidade em relação à germinação inicial. 


\section{Resultados e discussão}

Os meios analisados se mostraram capazes de promover e sustentar o processo de germinação de grãos de pólen de milho, sendo os meios de cultura M4 e M5 os mais eficientes (figura 1). Por outro lado, o meio de cultura M1 proporcionou menor germinação, provavelmente devido à ausência dos componentes importantes como o cálcio e boro, os quais têm sido indicados como elementos importantes na germinação de grãos de pólen (Rossel et al. 1999). Os demais meios se mostraram com eficiência intermediária (figura 1). Entre os constituintes que compõem o meio de cultivo, a concentração de sacarose é um fator fundamental, em que altas concentrações (acima de $30 \%$ ) podem inibir a germinação dos grãos de pólen. Segundo Rossel et al. (1999), a sacarose tem papel de controlador osmótico e nutricional, sendo que altas concentrações causam desequilíbrio, impedindo a germinação dos grãos de pólen.

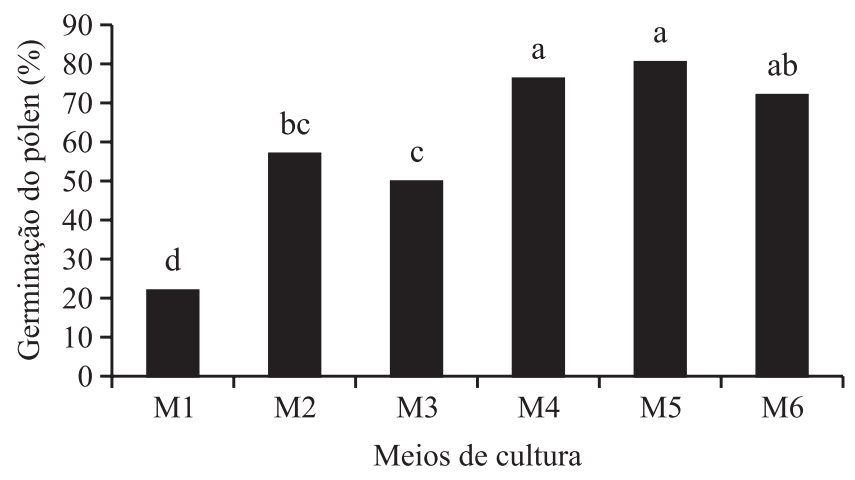

Figura 1. Germinação média de grãos de pólen de milho em seis meios de cultura. As barras com letras distintas diferiram significativamente pela estatística D.M.S. 5\%.

Figure 1. Average germination of maize pollen grains in six culture media. Bars with different letters differ statistically significantly by D.M.S. $5 \%$.

Os resultados do presente trabalho mostraram que, independentemente da presença de cálcio e ou boro, os meios contendo teor de sacarose entre 10 e $20 \%$ proporcionaram maior germinação, sendo que a concentração em torno de $10 \%$ é a mais indicada para a germinação in vitro de grãos de pólen de milho. Da mesma forma, o boro mostrou ser um elemento que maximiza a germinação in vitro e a concentração de $0,03 \%$ parece ser a melhor para muitas espécies, incluindo o milho. Os meios contendo cálcio (M5 e M6), que apresentaram um melhor crescimento, tiveram uma menor quebra do tubo polínico. Entre estes o M6 foi o mais eficiente mostrando que a concentração de $0,03 \%$ de $\mathrm{CaCl}_{2} \mathrm{H}_{2} \mathrm{O}$ proporciona um bom resultado.

A consistência do meio pode ser controlada utilizando ágar, que facilita na avaliação da germinação. Os meios de cultivo na forma líquida têm como desvantagem facilitar o desprendimento do tubo, dificultando a avaliação e promovendo uma subestimativa da viabilidade polínica, uma vez que grãos de pólen sem o tubo polínico são considerados como não germinados. Por outro lado, altas concentrações de ágar poderiam servir com barreira física, impedindo a germinação do tudo polínico. As melhores taxas de germinação foram obtidas com os meios M4, M5 e M6, independente da presença do ágar em sua constituição, sugerindo que não há impedimento do crescimento polínico na concentração de até $1 \%$.

Os tratamentos apresentaram uma alta de viabilidade antes da estocagem, variando de $98 \%$ a $75 \%$ dos grãos de pólens analisados em germinação in vitro, que foi diminuindo em até $40 \%$ após 30 dias de estocagem. A análise dos dados indicou uma interação significativa entre os fatores avaliados (desidratante e temperatura), permitindo uma análise de desidratantes dentro dos níveis de temperatura. As interações foram analisadas por regressão linear, sendo que em todos os tratamentos ocorreu uma diminuição significativa da viabilidade do pólen, ao longo do período de estocagem (figura 2). Entre os tipos de desidratação, o cloreto de cálcio proporcionou uma menor conservação da viabilidade

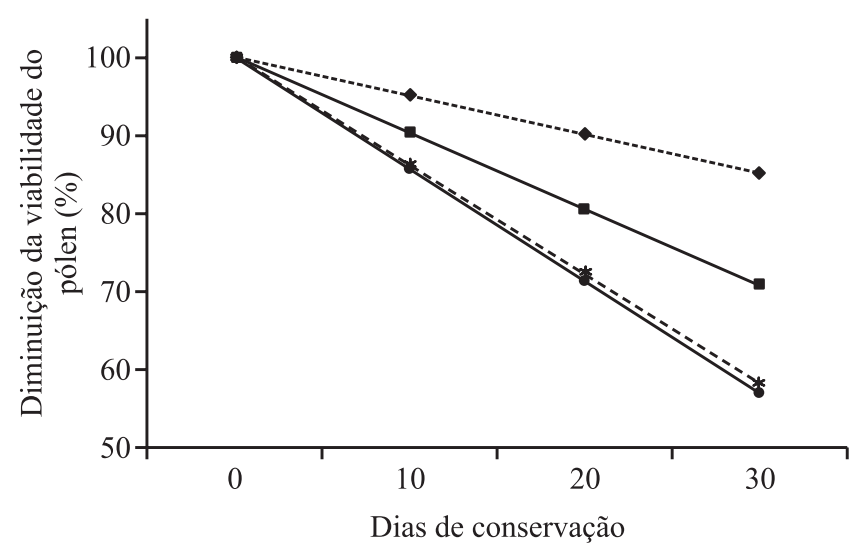

Figura 2. Viabilidade relativa da conservação de pólen, seguindo análise de regressão linear para combinação dos fatores temperatura e desidratante. $\left(-\cdots=\operatorname{Sílica}\left(4^{\circ} \mathrm{C}\right) ;--=\right.$ Sílica $\left(-20^{\circ} \mathrm{C}\right) ;-\bullet=\mathrm{CaC}_{12} \mathrm{H}_{2} \mathrm{O}\left(4^{\circ} \mathrm{C}\right) ;-*--=\mathrm{CaC}_{12} \mathrm{H}_{2} \mathrm{O}$ $\left.\left(-20^{\circ} \mathrm{C}\right)\right)$.

Figure 2. Relative viability of pollen conservation, following linear regression analysis for the combination of factors temperature and dehydrating. $\left(-\bullet--\operatorname{Silica}\left(4^{\circ} \mathrm{C}\right) ;--=\right.$ Silica $\left(-20^{\circ} \mathrm{C}\right) ;-\bullet=\mathrm{CaC}_{12} \mathrm{H}_{2} \mathrm{O}\left(4^{\circ} \mathrm{C}\right) ;--*--=\mathrm{CaC}_{12} \mathrm{H}_{2} \mathrm{O}\left(-20^{\circ} \mathrm{C}\right)$ ). 
do pólen em ambas as temperaturas estocadas. Esta acentuada diminuição é atribuída à baixa eficiência do $\mathrm{CaCl}_{2} 2 \mathrm{H}_{2} \mathrm{O}$ como desidratante, em que o cloreto de cálcio hidratado tem umidade de 20,8\%. Segundo Connor \& Towill (1993), a umidade do pólen pode ser manipulada com uso de sais saturados, nos quais os gametas tendem a equilibrar sua umidade com a umidade do sal. Assim, é possível presumir que os grãos de pólen sob o efeito do desidratante $\mathrm{CaCl}_{2} 2 \mathrm{H}_{2} \mathrm{O}$ teriam umidade em torno de $20 \%$. Os mesmos autores avaliaram grãos de pólen de milho fresco, seco (umidade 12\%) e estocado (umidade de 12\%) obtendo germinação de 45\%, 49\% e $39 \%$, respectivamente. Resultados similares foram encontrados por Barnabás et al. (1988) em que umidade de $18 \%$ e de $10 \%$ tiveram baixa fertilização a campo e umidade de $13 \%$ proporcionou maior fertilização.

$\mathrm{Na}$ conservação de pólen de milho, os melhores resultados já publicados foram de $72 \%$ de germinação, com temperaturas baixas, de $4{ }^{\circ} \mathrm{C}$ a $-196{ }^{\circ} \mathrm{C}$, com umidade de 29\% (Alvim, 2008). Por outro lado, a sílica gel tem um indicativo de umidade, onde coloração azul indica umidade de $10 \%$ e incolor, umidade de $20 \%$. A sílica gel contendo os grãos de pólen não apresentou mudanças na coloração, indicando uma umidade próxima a $10 \%$. Esta umidade proporcionou maior conservação da viabilidade do pólen. Segundo Barnabás et al. (1988) a desidratação é o principal fator na conservação de microgametófitos em plantas, onde na hidratação do pólen ocorre uma diminuição ou destruição da camada de lipídio da parede do gameta, provocando assim sua inviabilidade. Ferreira et al. (2007) mostraram que a quantidade elevada de água no pólen de milho diminui de forma drástica a viabilidade do pólen quando estocado em baixas temperaturas.

A temperatura de conservação de pólen mostrou ser outro fator de extrema importância. Por exemplo, Davide et al. (2009) analisaram a estocagem de pólen de milho na temperatura de $-10^{\circ} \mathrm{C}$ e os resultados mostraram a baixa viabilidade na germinação do tubo polínico. Nesse sentido, os resultados do presente trabalho mostram que a temperatura de estocagem de $4{ }^{\circ} \mathrm{C}$, com pólen desidratado com sílica proporcionam maior viabilidade de pólen, podendo este método ser empregado em programas de melhoramento para permitir cruzamentos entre genótipos com sincronismo diferenciado.

A estocagem de pólen desidratado e conservado em baixa temperatura permite manter a viabilidade por um período de 30 dias. Esses grãos de pólen podem ser utilizados em programas de melhoramentos para assistir cruzamentos entre genótipos de difícil sincronismo reprodutivo.

\section{Referências bibliográficas}

AKIHAMA, T., OMURA, M. \& KOZAKI, I. 1978. Further investigation of freezer-drying for deciduous fruit tree pollen. In Long term preservation of favorable germoplasm in arboreal crops (T. Akihama \& K. Nakajima, eds.). Kokusai Print Service, Tokyo, p.1-7.

ALEXANDER, M.P. 1969. Differential staining of aborted and non aborted pollen. Stain Technology 44: 117-122.

ALEXANDER, M.P. 1980. A versatile stain for pollen from fungi, yeast and bacteria. Stain Technology 55: 13-18.

ALVIM, P.O. 2008. Variabilidade e Conservação de grãos de pólen de milho. Dissertação de mestrado, Universidade Federal de Lavras, Lavras.

BARNABÁS, B., KOVACS, B., ABRANKI, A. \& PFAHLER, P. 1988. Effect of pollen storage by drying and deep-freezing on the expression of different agronomic traits in maize (Zea mays L.). Euphytica 39: 221-226.

COLAS, F. \& MERCIER, S. 2000. Évaluation et maintien de la viabilité des polens utilisés dans le programme d' amélioration des arbres. Forêt Quebéc, Charlesbourg.

CONNOR, F.K. \& TOWILL, L.E. 1993. Pollen-handling protocol and hydration/dehydration characteristics of pollen for application to long-term storage. Euphytica 68:77-84.

DAVIDE, L.M.C, PEREIRA, R.C., ABREU, G.B., SOUZA, J.C. \& PINHO, E.V.R.V. 2009. Viabilidade de pólen de milho em diferentes períodos de armazenamento em baixa temperatura. Revista Brasileira de Milho e Sorgo 8:199-206.

FER, W.R. \& HADLEY, H.H. 1980. Hybridization of crop plants. American Society of Agronomy, Madison.

FEREIRA, C.A., PINHO, E.V.R.V., ALVIM, P.O., ANDRADE, V., SILVA, T.T.A. \& CARDOSO, D.L. 2007. Conservação e determinação da viabilidade de grão de pólen de milho. Revista Brasileira de Milho e Sorgo 6:159-173.

GALLETA, G.J. 1983. Pollen and seed management. In Methods in fruits breeding (J.N. Moore \& J. Janick, eds.). Purdue University Press, Indiana, p.23-47.

HUGHES, H.G. \& LEE, C.W. 1991. Low-temperature preservation of Clianthus formosus pollen. HortScience 26:1411-1412.

MIRANDA, P.A. \& CLEMENT, C.R. 1990. Germination and storage of pejibaye (Bactris gasipaes) palmae pollen. Revista de Biologia Tropical 38:29-33.

PFAHLER, P.L. 1967. In vitro germination and pollen tube growth of maize (Zea mays L.) pollen II. Pollen source, calcium and boron interactions. Canadian Journal of Botany 46:235-240. 
PIO, L.A., RAMOS, D.J., PASCAL, M., JUNQUEIRA, K.P., SANTOS, F.C. \& RUFINI, J.C.M. 2007. Viabilidade do pólen de laranjas doces em diferentes condições de armazenamento. Ciência e Agrotecnologia 31:147-153.

ROSSEL, P., HERRERO, M. \& SAÚCO, G. 1999. Pollen germination of cherimoya (Annona cherimola Mill.) in vitro characterization and optimization of in vitro germination. Scientia Horticulturae 81:251-265.

SOUZA, V.A. 1988. Manejo e viabilidade do pólen de Eucalyptus spp. Dissertação de mestrado, Universidade de São Paulo, Piracicaba.
SPRAGUE, J.R. \& JOHNSON, V.W. 1977. Extraction and storage of loblolly pine (Pinus taeda) pollen. In Proccedings of 14 Southern Forest Tree Improvement Conference. Eastern Tree Seed, Macon, p.20-27.

STANLEY, R.G. \& LINSKENS, H.F. 1974. Pollen: biology, biochemistry and management. Springer Verlag, New York.

THOMPSON, A.H. \& BATJER, L.P. 1950. The effect of boron in the germination medium on pollen germination and pollen tube growth of several deciduous tree fruits. Proceedings of the American Society for Horticultural Science 56:227-230. 